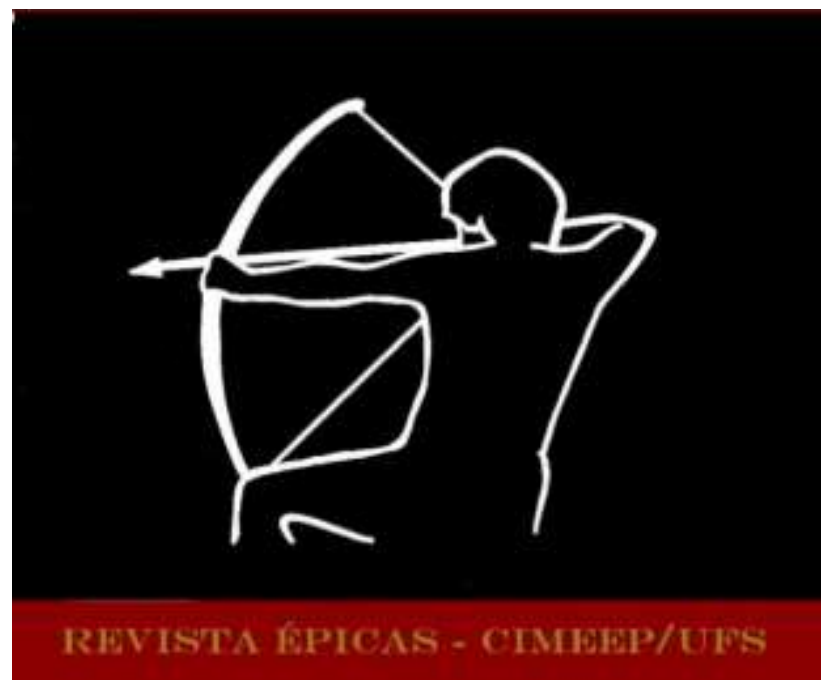

MARRERO-FENTE, Raúl. Orígenes de uma etiologia cubana em Espejo de paciencia (1608) de Silvestre Balboa. In: Revista Épicas. Ano 5, N. 9, Jun 2021, p. 13-26. ISSN 2527-080-X. DOI: http://dx.doi.org/10.47044/2527-080X.2021v91326

\title{
ORÍGENES DE UNA ETIOLOGIA CUBANA EN ESPEJO DE PACIENCIA (1608) DE SILVESTRE DE BALBOA ${ }^{1}$
}

\author{
BEGINNINGS OF CUBAN ETIOLOGY IN \\ ESPEJO DE PACIENCIA (1608) BY SILVESTRE DE BALBOA
}

\author{
Raúl Marrero-Fente ${ }^{2}$ \\ University of Minnesota/CIMEEP
}

RESUMEN: Este trabajo examina la construcción de una etiología o fábula de los orígenes por Silvestre de Balboa en Espejo de paciencia (1608). A partir del uso de la mitología clásica, Balboa asigna a la naturaleza cubana un valor simbólico nuevo que permite ver el paisaje en función de un sentimiento autóctono insular, marcando la diferencia con el paisaje europeo.

Palabras claves: Etiología; Silvestre de Balboa; Espejo de paciencia; poesía épica; mitología clásica.

ABSTRACT: This work examines the construction of an etiology or fable of origins by Silvestre de Balboa in Espejo de paciencia (1608). From the use of classical mythology, Balboa assigns a new symbolic value to Cuban nature that allows us to see the landscape based on an insular autochthonous feeling, marking the difference with the European landscape.

Keywords: Etiology; Silvestre de Balboa; Espejo de paciencia epic poetry; classical mythology.

\footnotetext{
1 Una version en inglés de este trabajo fue publicada en "Classical Epyllion and Tropical Cornucopia in Silvestre de Balboa's Espejo de paciencia." The Rise of Spanish American Poetry (1500-1700). Eds. Rodrigo Cacho and Imogen Choi. Oxford: Legenda, 2019. 239-252.

2 Doctor en Literaturas Hispánicas (University of Massachusetts, 1997). Catedrático de Literaturas Hispánicas y Derecho en la Universidad de Minnesota, E.E. U.U. Miembro del GT 5 del CIMEEP. rmarrero@umn.edu. ORCID: https://orcid.org/0000-00015691-757X.
} 


\section{Introducción}

Espejo de paciencia de Silvestre de Balboa (Gran Canaria, 1563-Cuba, ¿1649?) es un poema escrito en 1608 para conmemorar el secuestro y liberación del obispo de Cuba fray Juan de las Cabezas Altamirano ocurrido el 29 de abril de 1604 en las cercanías de la villa de Bayamo en Cuba. ${ }^{3}$ El poema tiene dos cantos. El primero narra el secuestro y cautiverio del obispo Cabeza por piratas franceses. El primer canto termina con la liberación del obispo, después del pago de un enorme rescate. El segundo canto relata el combate entre los criollos y los piratas franceses, que finaliza con la victoria de los criollos. Tras el secuestro del obispo Cabezas, los piratas franceses piden al pueblo de Bayamo un recate para liberarlo. Los aldeanos prometen pagar, pero en secreto preparan una emboscada. Bajo el liderazgo de Gregorio Ramos, un grupo de veintidós vecinos de Bayamo entablan una escaramuza contra los piratas franceses y los derrotan. En este combate el esclavo africano Salvador Golomón mata a Gilberto Girón, y por eso Silvestre de Balboa pide en el poema la emancipación del esclavo. Esta escena es la primera representación literaria de un esclavo africano en la literatura cubana.

El poema es la primera obra conocida de la literatura cubana. Después de dos siglos de estar perdido, fue descubierto en 1836 por el crítico literario José Antonio Echevarría en la biblioteca de la Sociedad de Amigos del País de La Habana. La primera edición completa se publicó en el siglo XX. En este trabajo examino la representación de la naturaleza cubana en el poema de Balboa, y la apropiación por el poeta del género bucólico para crear una etiología de lo cubano que renueva los modelos de la poesía épica colonial de Hispanoamérica ${ }^{4}$.

\section{Bucolismo de signo americano: una cornucopia tropical}

La sección final del canto I de Espejo de paciencia narra la escena de los seres mitológicos y la ofrenda de la cornucopia tropical al obispo Cabezas Altamirano. El género bucólico sirve de marco al episodio, expresado formalmente en octavas. A diferencia de los modelos de Garcilaso de la Vega, Alonso de Ercilla, Gabriel Lobo Lasso y Pedro de Oña, no hay elementos típicos de la lírica amorosa porque el personaje principal es una autoridad religiosa, pero se mantiene el formato retórico de la descripción de la naturaleza. La escena se inicia con un locus amoenus (CURTIUS, 2004, p. 207) a través del motivo de las "verdes yerbas y esmaltadas flores" (BALBOA, 2010, p. 110) de ascendencia garcilasiana; el monte habitado por diversas especies de seres mitológicos; el recibimiento de los semicapros, sátiros, faunos y silvanos quienes hacen la primera ofrenda de la cornucopia tropical: las frutas guanábanas, jijiras y

\footnotetext{
${ }^{3}$ Sobre el poema de Silvestre de Balboa ver los estudios de Saínz, Goergen, Marrero-Fente, (2008), y Cruz-Taura.

${ }^{4}$ Sobre las características del género de la poesía épica colonial en Hispanoamérica ver Marrero-Fente (2017).
} 
caimitos; luego salen las napeas y hacen su ofrenda mixta de animales, plantas, flores, frutas y vegetales: papagayos, flores de café, maíz, tabaco, mameyes, piñas, tunas, aguacates, plátanos, mamones y tomates. Aparecen las hamadríades y cuatro dríadas que presentan una ofrenda de frutas, plantas, flores, y árboles: siguas, macaguas, pitajayas, birijí y jaguas; seguidas de las náyades, y su obsequio de los frutos del mar: jiguagua, dajao, lisa, camarones, biajacas y guabinas; a continuación, vienen las efedríades; y las límniades que regalan las jicoteas de Masabo; luego la aclamación de los centauros y sagitarios; y finalmente, las oréades ofrecen iguanas, patos y jutías. La sección termina con la escena de la parada musical, uno de los tópicos del género bucólico.

Aunque Balboa sigue las convenciones del locus amoenus, no hay un elenco de árboles, como en los poemas de Lobo Lasso y Oña, en su lugar menciona a las divinidades asociadas a los árboles, fuentes, estanques, montañas, selvas y bosques, ofreciendo una interpretación novedosa del motivo de la selva amoena (OSUNA, 1969, p. 377-407; OÑA, 2014, p. 187). Para Lola González el poema de Balboa se aparta de la tradición épica del Nuevo Mundo porque, a diferencia de otros modelos, en especial el de Ercilla en La Araucana, muestra una predilección por la naturaleza americana (GONZÁLEZ, 1998, p. 13). Siguiendo la tradición heredada desde el bucolismo virgiliano los poetas prefieren la descripción de la naturaleza dictada desde los cánones clásicos, reactualizados en el Renacimiento. Lola González destaca, además, la peculiaridad de Balboa de representar la naturaleza dentro de un bucolismo pastoril, aunque sigue el "canon descriptivo de la época" (GONZÁLEZ, 1998, p. 16). Entre las alusiones a la naturaleza destaca González las de carácter temático, y apunta las conocidas influencias de Garcilaso, Barahona, y Cairasco. Pero aclara que, a pesar de seguir las convenciones del tópico, Balboa introduce una nota realista en las descripciones de la naturaleza. De esta manera refuta González las tesis de José María Chacón y Calvo, quien estableció la imagen para la historiografía literaria de un poema donde se habla poco de la naturaleza isleña. Para González el tratamiento de la naturaleza en Balboa puede ser visto como la creación de una "nueva selva mixta", al estilo de las recogidas por la retórica medieval, que aporta una extraordinaria novedad a la épica colonial, y constituye la originalidad mayor del poema de Balboa (GONZÁLEZ, 1998, p. 19).

La imagen del paisaje en Espejo de paciencia apela a varios sentidos: visual (colores de las flores y frutas); olfativo (olores de las flores y frutas); y auditivo (canto de las ninfas y la música de los faunos). La descripción de la naturaleza constituye una renovación del tópico en la poesía épica colonial. A diferencia de Ercilla, Lobo Lasso y Oña, el paisaje descrito por Balboa inserta flores, plantas, frutas, árboles y animales de la naturaleza insular. Es un paisaje realista por la descripción de la naturaleza, y a la misma vez, es un paisaje maravilloso por la presencia de los seres mitológicos. Este paisaje mixto es una novedad 
de Balboa ausente en la Primera parte de las Elegías de varones ilustres de Indias, de Juan de Castellanos (Madrid, 1589) porque este separa en dos cantos diferentes la cornucopia tropical y los seres mitológicos. Por otra parte, es un locus amoenus incultus porque se trata de una naturaleza salvaje que no ha sido modificada por la agricultura y representa el tópico de la riqueza de los trópicos, por medio del símbolo del cuerno de la abundancia.

A diferencia del canto XVII en La Araucana que introduce la escena maravillosa por medio del sueño del poeta, en la obra de Balboa el obispo aparece por sí mismo, sin ayuda de ningún recurso sobrenatural. Balboa emplea la adjetivación anticipada al sustantivo: "las verdes yerbas y esmaltadas flores," aludiendo a los versos de La Araucana (ERCILLA, 1993, p. 510) y a los conocidos epítetos de las églogas garcilasianas y del bucolismo petrarquesco (LERNER, 1978, p. 206). La llegada del obispo es similar a la de Hernán Cortés en el canto XI de Mexicana de Lobo Lasso de la Vega por medio del recurso de reanudación de la acción interrumpida al final del canto anterior: "el ancho prado, verde y florecido,/de diversos matices esmaltado,/con apacible Céfiro enviaba,/que suave a toda parte respiraba" (LOBO, 2005, p. 313). También presente en Arauco domado de Pedro de Oña: “En todo tiempo el rico y fértil prado/ está de yerva y flores guarnescido,/ las cuales muestran siempre su vestido" (OÑA, 2014, p. 191). Como destaca Avalle-Arce, "la naturaleza descrita no corresponde a la circunstancia real del poeta, a su Chile natal, sino que viene directamente de la tradición literaria. En el Arauco domado los cánones poéticos desplazan la realidad física... Los prados que transitan araucanos y españoles son de neto garcilasismo, poetizados de espaldas a la realidad física, con la tradición literaria obsesivamente ante los ojos" (AVALLEARCE, 2000, p. 73). La estrofa de Balboa alude a las "propiedades mágicas que tienen determinados elementos de la naturaleza," (VEGA, 1995, p. 473) y a los efectos terapéuticos del paraje ameno (Idem, Ibidem). El animismo apuntado por Rafael Lapesa está presente en Balboa, quien usa un "estilo enumerativo" (LARA, 1994, p. 246) para otorgarle a la flora y fauna locales un protagonismo poético nuevo, algo similar a la poesía de Barahona de Soto, donde "la cornucopia enmarcada en un bodegón poético de frutas y animales" (Ibidem, p. 251) organiza un "cortejo frutal." (Ibidem, p. 258). Encabezan este cortejo semicapros, sátiros, faunos y silvanos. Los seres mitológicos en Balboa recuerdan el Cuarto canto de la Elegía I de la Primera parte de las Elegías de varones ilustres de Indias de Juan de Castellanos, cuando los españoles describen a los primeros indígenas americanos en las islas Lucayas. Castellanos compara a los habitantes de las Américas con seres de la mitología clásica; Balboa no menciona a los indígenas, solamente habla de los seres mitológicos como habitantes de los campos cubanos. La escena bucólica en Balboa no es un adorno, el obispo forma parte de esta, está integrado a ella y los personajes mitológicos se dirigen a él con los presentes de la tierra. También en este caso podemos decir que "los 
términos enumerados perfilan las dimensiones reales del paisaje y aluden a una geografía, si no real, coherente con el juego entre ficción y mundo" (ROSES, 2002, p. 286). El pasaje tiene antecedentes en Ercilla: "cantaban dulces letras amorosas,/ con cítaras y liras en las manos/ diestros sátiros, faunos y silvanos," (ERCILLA, 1993, p. 510) quien a su vez sigue a Garcilaso en la Elegía I, vv. 169: "Sátiros, faunos, ninfas, cuya vida/ sin enojos se pasa;" (VEGA, 1995, p. 100) y la Égloga 2, vv. 1157: "sátiros y silvanos soltá todos." (VEGA, 1995, p. 194). Motivo imitado por Juan de Castellanos : "Si son sátiros estos, ó silvanos,/ Y ellas aquellas ninfas de Aristeo:/ O son faunos lascivos y lozanos;" (CASTELLANOS, 1997, p. 34) repetido en Lobo Lasso: "Sátiros, Faunos, Ninfas campesinas;" (LOBO, 2005, p. 312) y en Pedro de Oña: "de sátiros y faunos perseguidas" (OÑA, 2014, p. 192), pero en ellas no hay interacción entre el personaje principal y los personajes mitológicos. En el poema de Balboa la escena puede verse como una alegoría de la subordinación de los símbolos paganos al cristianismo y un ejemplo de bucolismo cristiano. La escena alude al modelo clásico de las Metamorfosis, 1. 193-194: "Tengo a mi servicio semidioses, tengo divinidades campestres, Ninfas y Faunos y Sátiros, y también Silvanos habitantes de los montes" (OVIDIO, 2009, p. 203). Balboa también incluye a los silvanos, que en la mitología clásica eran divinidades de los campos y los bosques, protectores de los sembrados (Horacio, Epodos 2.22). Los sátiros y las ninfas son los llamados dioses menores y eran mortales, contrarios a los dioses olímpicos que eran inmortales (Ruiz de Elvira, 1995, p. 94). Como señala Vicente Cristóbal, las deidades silvestres son patrocinadoras del género bucólico (CRISTÓBAL, 2002, p. 87-104). El poema de Balboa pertenece al género pastoril, pero el número de ninfas y su orden en el poema es distinto. Aunque existen numerosos textos poéticos que Balboa pudo imitar, no tenemos certeza de su conocimiento de estos, con la excepción del poema de Juan de Castellanos, con el cual comparte evidente similitud textual.

La escena de la bienvenida al obispo combina dos pasajes del poema de Castellanos: la referencia a los seres mitológicos en la Elegía II y la escena de la enumeración de las frutas tropicales en la Elegía XIV. Castellanos modifica el locus clásico del paraje ameno con la incorporación de la naturaleza americana, por medio de la escena de la cornucopia tropical que presenta una enumeración de la flora y fauna de la isla Margarita:

Ay muchos higos, uvas, y melones, Dignísimos de ver mesas de reyes, Pitahayas, guanábanas, anones, Guayabas, y guaraes, y mameyes: Hay chica, cotuprises, y mamones, Piñas, curibijuris, caracueyes, Con otros muchos mas que se desechan $E$ indios naturales aprovechan.

(CASTELLANOS, 1997, p. 294) 
El primer verso comienza con la referencia a tres frutas (higos, uvas, melones) de acuerdo con la preceptiva clásica de los modelos del paisaje idílico de la poesía bucólica. Este tropo es rápidamente sustituido por la incorporación de una docena de frutas americanas (pitahayas, guanábanas, anones, guayabas, guaraes, mameyes, chica, cotuprises, mamones, piñas, curibijures, caracueyes), en forma de catálogo o muestrario de la riqueza del lugar.

La influencia de los clásicos latinos en Balboa está mediada por la contaminatio de los modelos de Garcilaso, Barahona, Sannazaro y Castellanos, entre otros. Esta deuda se expresa por medio de unos tópicos bucólicos estructurados que arman el episodio del obispo y los seres mitológicos, "enmarcado en una presentación del paisaje, realzado hasta constituir un locus amoenus," localizado "en un escenario familiar al poeta" (CRISTÓBAL, 2002, p. 96). Balboa también sigue la renovación de Barahona de "presentarnos a ninfas cantando y no a pastores," a imitación de la Égloga III de Garcilaso (CRISTÓBAL, 2002, p. 96) y presenta a unos centauros quienes "de dos en dos cantan a solas;" (BALBOA, 2010, p. 113) de esta manera introduce Balboa "el motivo del mágico poder de la música sobre la naturaleza" proveniente de Virgilio Égloga 8.1-5 y Garcilaso Égloga 1.4-6 (CRISTÓBAL, 2002, p. 97).

Balboa al igual que Garcilaso vincula el paisaje con la tradición clásica y la mitología; pero otorga una nueva dimensión a la descripción de la naturaleza cuando agrega la flora y fauna de los trópicos. De esta manera el encuentro del obispo y los seres mitológicos alcanza un significado nuevo por la riqueza de los elementos de la tradición clásica junto al referente físico americano. Balboa muestra un nuevo repertorio a partir del motivo de la cornucopia incorporando un nuevo elenco de especies vegetales, junto a las frutas y animales, cada una de ellas relacionada con características sensoriales (color, olor, sabor, tacto), reactualizando el tópico clásico. Estamos en presencia de un catálogo arbóreo de plantas, vegetales y animales endémicos de América. Balboa describe la naturaleza por medio de un ornato mitológico y una exuberancia verbal localizada en un "rincón" "reducido" de los campos cercanos a Yara (FERNÁNDEZ, 2002, p. 231). También en Balboa hay "una poética de la intensificación", con el objetivo de lograr la "recreación de una naturaleza pródiga y sensorial" (Idem, Ibidem) expresada como "enumeración acumulativa" en la que se conjuga la tradición bucólica por medio de la variedad de árboles, plantas, y frutas junto a las fábulas mitológicas que los personajes de las ninfas y los faunos simbolizan. En Balboa predomina la insistencia en las características físicas de la naturaleza por medio de los "matices visuales" de la cornucopia con una función descriptiva y pictórica (FERNÁNDEZ, 2002, p. 235) La “instrumentalización de la naturaleza" es el eje central de la composición de Balboa, porque los elementos naturales sirven de base a la argumentatio de la ofrenda tropical por los seres mitológicos. De esta manera Balboa focaliza la atención del pasaje en el elenco frutal, desplazando la importancia de los seres 
mitológicos, quienes aparecen silenciosos. Es necesario aclarar que la ofrenda de la cornucopia sirve de alegoría reparadora por las transgresiones de los vecinos, responsables del cautiverio del obispo por los corsarios franceses. Más allá de las claves de interpretación política, Balboa también modifica el tópico porque incluye elementos descriptivos locales junto a mitológicos clásicos. De esta manera crea una etiología nueva a partir de la naturaleza americana, renovando el simbolismo original de la mitología clásica. Esta nueva etiología no proviene de la mitología ni del simbolismo de las plantas clásicas porque el elenco de árboles y plantas tropicales que aparece en Espejo de paciencia no existe en Europa. Balboa instrumentaliza con el lenguaje de la poesía épica la naturaleza cubana a partir de un verismo que calca o imita la realidad. De esta forma el poeta inicia una etiología de lo cubano, en la cual la naturaleza adquiere un papel fundamental en la definición de lo que se entiende por cubano. Estamos ante una construcción poética nacida de un entorno ecológico.

\section{Poesía épica en clave de crónicas de la conquista}

Las claves de interpretación en relación con la naturaleza americana no aparecen en la mitología clásica, sino en los cronistas de Indias, fundadores del discurso sobre la maravilla americana. Esta idea sobre la conexión entre el poema de Balboa y los textos de las crónicas de Indias fue sugerida por Lola González, en especial con el Sumario de la Natural Historia de las Indias de Gonzalo Fernández de Oviedo (1998, p. 19). En los textos de las crónicas de Indias, en especial en Anglería, Las Casas, Fernández de Oviedo y Gómara, encontramos los relatos de la nueva mitología americana. La imitación garcilasiana, soporte de la estructura general del pasaje, aparece contaminada por la imitación del poema de Juan de Castellanos, modelo épico inmediato de Balboa, elevando la naturaleza americana a la categoría de mito universal similar a los modelos clásicos. Entre los elementos renovadores de Balboa están la incorporación de las ninfas y faunos a la cornucopia tropical y su representación (que implica subordinación y labor), y la flora y fauna con su variedad sensorial. Estos segmentos descriptivos imponen una visión realista del paisaje expresado por medio de elementos locativos con una identificación concreta, desplazando de esta manera la convencionalidad del paisaje bucólico de los modelos virgilianos y garcilasianos.

Como señala Juan Montero entre 1560 y 1580 aumenta la publicación de églogas profanas y religiosas, "ya que el tratamiento religioso del genero gana considerable terreno en esos años y hasta final del siglo" (MONTERO, 2002, p. 201). La descripción de la naturaleza en el poema de Balboa también forma parte de esta tendencia religiosa del género bucólico, destacada por Antonio Prieto, en la cual el "paisaje bucólico en cuanto fondo o marco se acrecienta ... hasta fundamentar su novedad...con una percepción sensorial de la naturaleza que enfatiza sus dones en la misma sonoridad del vocablo que los designa" 
(PRIETO, 1998, p. 699). Este pasaje es el más famoso del poema por la riqueza de las descripciones y por la mezcla del mundo clásico y el insular, que ponen de manifiesto la novedad de la cultura americana. La complejidad de los modelos anotados no debe ser entendidos como una serie de conexiones superficiales, sino como resultado de la tendencia inclusiva de la épica, que busca representar una visión enciclopédica de la cultura que la produce (BEISSINGER, TYLUS, Y WOFFORD, 1999, p. 2). Este rasgo de inclusión aparece por medio del uso de varios recursos de la tradición literaria europea, que coexisten junto a la cultura local, expresada a través de una mitología y una naturaleza heterogéneas. Es esta tendencia la que permite a la poesía épica establecer conexiones entre diferentes culturas, de ahí que en el poema de Balboa la heterogeneidad cultural es uno de los modos de intercambio entre la cultura europea y la cultura local.

El primer verso comienza con la mención de tres frutas: guanábanas, jijiras y caimitos, imitando la preceptiva clásica sobre el paisaje en la poesía bucólica:

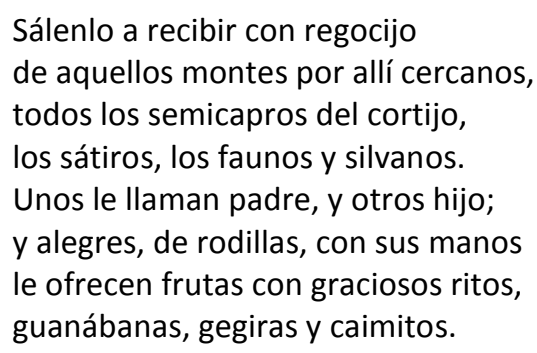

Vinieron de los pastos las napeas, y al hombro trae cada una un pisitaco, y entre cada tres de ellas dos bateas de flores olorosas de navaco. De los prados que acercan las aldeas vienen cargadas de mehí y tabaco, mameyes, piñas, tunas y aguacates, plátanos y mamones y tomates.

Bajaron de los árboles en naguas las bellas amadríades hermosas, con frutas de siguapas y macaguas y muchas pitajayas olorosas.

De virijí cargadas y de jaguas salieron de los bosques cuatro diosas, Dríades de valor y fundamento, que dieron al Pastor grande contento.

De arroyos y de ríos a gran prisa salen náyades puras, cristalinas, con mucho jaguará, dajao y lisa, camarones, biajacas y guabinas; y mostrando al pastor con gozo y risa 


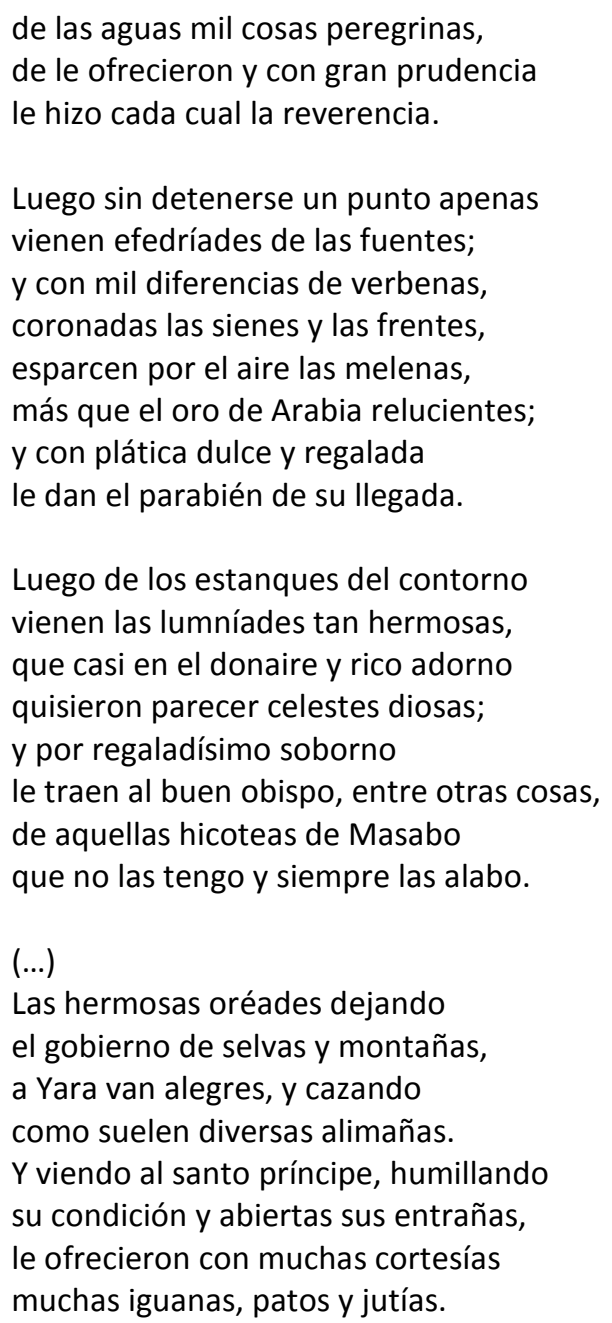

La novedad en este caso es que se trata de frutas y flores americanas, incorporadas en forma de catálogo o muestrario de la riqueza del lugar. La naturaleza americana irrumpe en el poema, por medio del recurso de la cornucopia tropical. Este motivo fue modificado por Balboa a partir de la experiencia de vivir en Cuba. El resultado es una escena que imita a los modelos clásicos y renacentistas con la marca diferenciadora de un doble registro: por un lado, hay una lectura culta que privilegia el valor sonoro del verso por encima del valor significante (LARA, 1994, p. 247), siguiendo la tradición de la poesía épica clásica. Esta primacía por el "exotismo sonoro" (LARA, 1994, p. 249) combina en la enumeración léxicos indígenas y castellanos; y por el otro, hay una lectura sensorial, de un lector que reconoce la realidad americana descrita en el poema. En este universo de lectores, Balboa se sitúa como observador y traductor privilegiado, capaz de usar los códigos culturales europeos y sintonizarlos a la realidad americana. Esta singular experiencia de un español que vive en América queda plasmada en los versos 
que describen la cornucopia tropical, motivos insertos dentro de la pastoral que enmarca las escenas bucólicas del encuentro del obispo con los seres mitológicos.

De acuerdo con los modelos de imitación poética, Balboa usa vocablos indígenas de la flora y la fauna insular para describir la abundante naturaleza americana. La presencia de la fauna y la flora isleña en el poema sigue una tradición modélica que busca renovar la descripción del paisaje ideal proveniente del género de la égloga bucólica clásica de Teócrito y Virgilio, transformada por la égloga renacentista de Garcilaso. Entre los cambios más significativos pueden señalarse el uso de léxicos americanos y las descripciones acumulativas, las cuales, por su reiteración, buscan insistir en la abundancia y riqueza de las tierras americanas. Es decir, Balboa crea una imagen del paisaje diferente, modelada en las normas del género de la égloga bucólica clásica y renacentista, donde la fauna, la flora y los frutos tropicales tienen una visualización casi corpórea. Los elementos locativos del paisaje en el poema de Balboa se organizan por medio de un léxico indigenista contextualizado por los modelos de imitación de la poesía clásica y renacentista, y dan lugar a una etiología, es decir, a una fábula fundacional. Esta etiología americana, modelada en el motivo de la cornucopia tropical a partir de la imitación de las Metamorfosis de Ovidio y de la poesía de Garcilaso tiene como función construir un relato fundacional de lugares geográficos prominentes, de los árboles, las flores y las frutas americanas. Esto explica la relación entre las etiologías y la descripción del paisaje, y de forma especial, plantean la pregunta sobre cómo debe interpretarse este paisaje (WOFFORD, 1999, p. 242). La transformación de las convenciones retóricas sobre la descripción del paisaje en los versos que comentamos, es la innovación principal de Balboa. El autor logra presentar al lector un paisaje diferente al de la tradición literaria europea, tarea que cumple especialmente con el uso de un léxico indígena para nombrar las frutas. De acuerdo con Michael Woods, el motivo de la cornucopia insiste en el preciosismo y preferencia en el detalle de la descripción, por medio de tres recursos (WOODS, 1978, p. 99-102). En primer lugar, con la idea de que el poeta está verdaderamente interesado en el tema. En segundo lugar, la necesidad de hacer enumeraciones amplificativas para demostrar la abundancia y riqueza de la naturaleza determina las descripciones acumulativas. Por eso Balboa incluye las estrofas de la cornucopia con un muestrario de frutas, vegetales y animales de deliciosas connotaciones gastronómicas. Este catálogo, junto al inventario de árboles y plantas insulares, modelado en la tradición ovidiana, producen un sentimiento territorial, porque se asocian al mundo americano ya que en el poema aparecen representados como productos endémicos de la zona geográfica descrita. Este sentimiento territorial pone de manifiesto la estrecha relación del poeta con la naturaleza americana, y es una marca de diferencia importante entre las descripciones del paisaje en Balboa. En tercer lugar, el preciosismo de las descripciones permite concentrar la atención en los detalles, y su 
capacidad de maravillar. Este es el logro más importante de la renovación del motivo clásico de la cornucopia tropical en el poema. Balboa pone de manifiesto una sensibilidad poética nueva hacia el paisaje y la naturaleza americana en la cual, a pesar de las convenciones de los modelos de imitación poética (Teócrito, Ovidio, Virgilio, Garcilaso, Camões, Ercilla, Castellanos), el autor privilegia el uso de un léxico indigenista como recurso para resaltar la diferencia entre los elementos locativos americanos y europeos. Balboa describe poéticamente el paisaje, las flores, la fauna, las frutas y otros aspectos de la naturaleza americana, como una realidad nueva, representada literariamente como una maravilla porque no tiene equivalente en la realidad europea. En este sentido la obra de Balboa se inserta en la tradición de las crónicas de la conquista de América que presentan al Nuevo Mundo como una maravilla.

Al seguir los modelos de imitación poética, Balboa prefiere usar vocablos de la fauna y la flora insulares para distanciarse de sus modelos europeos, y encontrar un espacio poético nuevo desde el cual la voz poética alcanza a diferenciarse de sus antecesores. En una primera lectura esta imitación puede aparecer como una continuación de la tradición poética del género bucólico, pero una lectura detenida nos permite ver además que hay una búsqueda de la diferenciación de la subjetividad poética. Es decir, la presencia de la fauna y la flora isleña en el poema sigue una tradición que busca renovar la descripción del paisaje bucólico ideal a partir de la inclusión de elementos provenientes de la naturaleza americana. En este sentido, Balboa sigue la tradición del bucolismo europeo que tiene un fuerte valor simbólico. Aunque es necesario aclarar que el simbolismo del poema de Balboa no puede ser totalmente entendido desde la perspectiva europea de la época, porque no hay en la tradición de los modelos épicos un ámbito de referencia que incluya estos nuevos escenarios americanos y el vocabulario necesario para definirlos. Entre los cambios más significativos pueden señalarse, entre otros, la presencia de descripciones acumulativas de las frutas tropicales. Por lo tanto, Balboa consigue, a pesar del exotismo y extrañamiento de su descripción presentar una visión de un paisaje poético de acuerdo con las normas del género de la égloga, donde la fauna, la flora y los frutos tropicales alcanzan una visualización casi corpórea. Los elementos locativos del paisaje en el poema de Balboa se organizan en torno a los campos de Yara, pero en el pasaje de la ofrenda al obispo Cabezas también encontramos alusiones a otras regiones de la isla. El aspecto más significativo de la modificación de Balboa es que el plano de la realidad descrita sobrepasa, por su riqueza, los esquemas de los modelos literarios europeos. Es necesario insistir que una de las funciones de las etiologías en los poemas épicos es relatar el origen de lugares geográficos prominentes, de los árboles, las flores y las frutas. En este sentido Susanne Wofford señala que las etiologías tienen que ver con la descripción del paisaje en el poema, plantean la pregunta sobre cómo debe interpretarse este paisaje (WOFFORD, 1999, p. 242). En el poema de Balboa, la naturaleza americana aparece como 
elemento predominante frente a las convenciones literarias. Esta innovación se logra por la mención de la flora y la fauna tropicales, que se manifiestan como una naturaleza heterogénea en dos sentidos. En primer lugar, por su propia condición autóctona; $y$, en segundo lugar, por el lenguaje que nombra a esta flora y fauna, también formado por vocablos americanos.

Esta enumeración extensa de las frutas y animales cumple además con la función de enfatizar la autenticidad de los hechos narrados en el poema. Este era un recurso típico de la poesía de la época y alcanza su máximo desarrollo en el siglo XVII. Según aclara Michael Woods, el motivo de la cornucopia se caracteriza por su preciosismo y descripción detallada, a partir de dos momentos (WOODS, 1978, p. 100). En primer lugar, dando la impresión de que el poeta está cautivado por su tema, esto explica el énfasis de Balboa en la emoción, personificada en la bienvenida de los sátiros, ninfas, faunos y silvanos tributan al obispo. Balboa presenta a estos seres mitológicos en una intimidad con el obispo Cabezas Altamirano, que oscila entre los sentimientos de devoción cristiana y ambientación pagana, con escenas de adoraciones que incluyen la ofrenda de productos autóctonos de la fauna y flora insulares. En segundo lugar, la necesidad de hacer enumeraciones más extensas para demostrar la riqueza de la naturaleza determina las descripciones acumulativas. Así, vemos la escena de la cornucopia en el poema de Balboa que muestra en rápida sucesión un listado de frutas, vegetales y animales de deliciosas connotaciones gastronómicas: guanábanas, caimitos, mameyes, piñas, aguacates, plátanos, mamones, tomates, dajao, lisa, camarones, biajacas, guabinas, jicoteas, iguanas, patos y jutías. El preciosismo de las descripciones permite concentrar la atención en los detalles y su capacidad de maravillar. El valor mayor del recurso de la cornucopia en Balboa es la capacidad de representar lo nuevo con lo conocido, en una mezcla que necesariamente implica una conciencia de la diferencia entre la naturaleza europea y la americana, vistas desde la perspectiva de América. Esta posición de la voz poética pone de manifiesto una sensibilidad hacia el paisaje y la naturaleza insulares en la que, a pesar de las convenciones de los modelos de imitación poética, Balboa mantiene la separación de los elementos americanos y europeos, que aparecen juntos, pero sin llegar a confundirse. Se destaca, en este caso de manera especial, la escena de las hamadríades en naguas donde la imagen poética se crea por una superposición de dos realidades opuestas, y en la que la presencia del vocabulario indígena sirve de signo de diferencia entre lo americano y lo peninsular. Esta superposición se alcanza por medio del símil de las hamadríades que tiene como objetivo resaltar los elementos diferenciantes entre ambas realidades, por un lado, las hamadríades recuerdan la tradición poética europea; mientras que las flores y frutas americanas, nombradas por medio de un vocabulario indígena, representan la realidad americana: 
Bajaron de los árboles en naguas

las bellas amadríades hermosas,

con frutas de siguapas y macaguas

y muchas pitajayas olorosas.

\section{Consideraciones finales}

Esta renovación del tema del paisaje en Balboa aparece además en la imitación del motivo del jardín edénico, de larga trayectoria desde la Arcadia clásica, transposición poética de un paraíso terrenal como lugar de felicidad y vida serena. La descripción de la naturaleza insular como un jardín edénico sigue las convenciones de fuente de descanso y satisfacción (GIAMATTI, 1966, p. 179). A diferencia de los jardines de la tradición literaria clásica (Virgilio, Eneida, VI; Bucólicas, III) y renacentista (Ariosto, Orlando furioso, X; Camões, Os Lusíadas, IX), Balboa introduce una innovación importante, porque "vestir a las ninfas con 'naguas', aparte de privilegiar lo americano al colocarlo como signo junto a lo culto y a lo clásico, 'cubaniza' a las ninfas, las hace tangibles y las coloca del lado americano" (GOERGEN, 1993, p. 78). En la imitación de Balboa el jardín es emblemático de una valoración ética siguiendo la preceptiva horaciana de las admoniciones y los preceptos de la épica cristiana de Tasso. La inclusión de las figuras mitológicas en el escenario americano es un recurso adoptado por Balboa para cumplir con las normas del género; pero pone de manifiesto el conflicto causado por la apropiación de la maquinaria mitológica, siguiendo los preceptos de Tasso de subordinar la maquinaria mitológica pagana a las necesidades de la épica cristiana.

\section{Referencias bibliográficas}

AVALLE-ARCE, Juan Bautista. La épica colonial. Pamplona: Universidad de Navarra, 2000.

BALBOA, Silvestre de. Espejo de paciencia. Ed. Raúl Marrero-Fente. Madrid: Cátedra, 2010.

BEISSINGER, Margaret, Jane TYLUS y Susanne WOFFORD. Epic Traditions in the Contemporary World. The Poetics of Community. Berkeley: University of California Press, 1999.

CASTELLANOS, Juan de. Elegías de varones ilustres de Indias. Ed. Gerardo Rivas Moreno. Bogotá: G. Rivas Moreno, 1997.

CURTIUS, Ernst Robert. Literatura europea y Edad Media latina. México: FCE, 2004.

CRUZ-TAURA, Graciella. Espejo de paciencia y Silvestre de Balboa en la historia de Cuba. Madrid: Iberoamericana, 2009.

CRISTÓBAL, Vicente. La tradición clásica en la poesía de Luis Barahona de Soto. In: De saber poético y verso peregrino. La invención manierista en Luis Barahona de Soto, ed. José Lara Garrido. Málaga: Universidad de Málaga, 2002, pp. 87-104.

ERCILLA Y ZÚÑIGA, Alonso de. La Araucana. ed. Isaías Lerner. Madrid: Cátedra, 1993. 
FERNÁNDEZ DOUGNAC, José. Naturaleza, topografía y mito en la poesía de Barahona de Soto. In: De saber poético y verso peregrino. La invención manierista en Luis Barahona de Soto. ed. José Lara Garrido. Málaga: Universidad de Málaga, 2002, pp. 229-256.

GIAMATTI, A. B. The Earthly Paradise and the Renaissance Epic. Princeton: Princeton University Press, 1966.

GOERGEN, Juana. Literatura fundacional americana: El Espejo de paciencia. Madrid: Pliegos, 1993.

GONZÁLEZ, Lola. La naturaleza en el Espejo de paciencia de Silvestre de Balboa. In: Arrabal 1 (1998), 1322.

HORACIO. Odas y Epodos, ed. Manuel Fernández-Galiano y Vicente Cristóbal López. Madrid: Cátedra, 1990.

LARA GARRIDO, José. La poesía de Luis Barahona de Soto (Lírica y épica del Manierismo). Málaga: Servicio de Publicaciones, Diputación Provincial de Málaga, 1994.

LERNER, Isaías. 'Garcilaso en Ercilla', Lexis 2 (1978), 201-221.

LOBO LASSO DE LA VEGA, Gabriel. De Cortés valeroso y Mexicana. ed. Nidia Pullés-Linares. Madrid: Iberoamericana, 2005.

MARRERO-FENTE, Raúl. Poesía épica colonial del siglo XVI. Historia, teoría y práctica. Madrid/Frankfurt am Main: Iberoamericana/Vervuert, 2017.

MARRERO-FENTE, Raúl. Epic, Empire and Community in the Atlantic World: Silvestre de Balboa's Espejo de paciencia. Lewisburg: Bucknell University Press, 2008.

MONTERO, Juan. La égloga en la poesía española del siglo XVI: panorama de un género (desde 1543). In: La égloga. ed. Begoña López Bueno. Sevilla: Universidad de Sevilla, 2002, pp. 183-206.

OÑA, Pedro de. Arauco domado. ed. Ornella Gianesin. Pavia: Ibis, 2014.

OSUNA, Rafael. Un caso de continuidad literaria: La silva amoena. In: Thesaurus 24 (1969), 377-407

OVIDIO. Metamorfosis. eds. Consuelo Álvarez y Rosa María Iglesias. Madrid: Cátedra, 2009.

PRIETO, Antonio. La poesía española del siglo XVI. II. Aquel valor que respetó el olvido. Madrid: Cátedra, 1998.

ROSES, Joaquín. Retórica y naturaleza en la Égloga cuarta de Barahona de Soto. In: De saber poético y verso peregrino. La invención manierista en Luis Barahona de Soto, ed. José Lara Garrido. Málaga: Universidad de Málaga, 2002, pp. 229-256.

RUIZ DE ELVIRA, Antonio. Mitología clásica. Madrid: Gredos, 1995.

SAÍNZ, Enrique. Silvestre de Balboa y la literatura cubana. La Habana: Letras Cubanas, 1982.

VEGA, Garcilaso de la. Obra poética y textos en prosa. ed. Bienvenido Morros. Barcelona: Crítica, 1995. VIRGILIO. Eneida. ed. José Carlos Fernández Corte. Madrid: Cátedra, 2006.

WOFFORD, Susanne. Epic and the politics of the origin tale: Virgil, Ovid, Spenser, and Native American aetiology. In: Epic Traditions in the Contemporary World: The Poetics of Community. ed. Margaret Beissinger, Jane Tylus, y Susanne Wofford. Berkeley: University of California Press, 1999, pp. 239-269.

WOODS, Michael J. The Poet and the Natural World in the Age of Góngora. Oxford: Oxford University Press, 1978. 